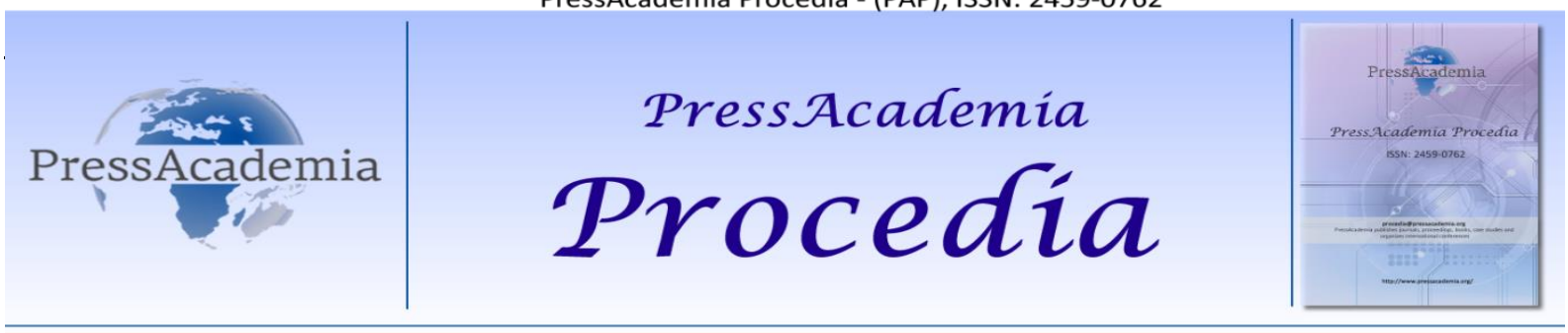

Istanbul Finance Congress (IFC), November 2-3, 2017, Istanbul, Turkey

\title{
EVALUATION OF IFRS 17 INSURANCE CONTRACTS STANDARDS FOR INSURANCE COMPANIES
}

DOI: 10.17261/Pressacademia.2017.745

PAP-IFC- V.6-2017(9)-p.48-50

Serhat Yanik ${ }^{1}$, Ece Bas ${ }^{2}$

${ }^{1}$ Istanbul University, Department of management, Istanbul, Turkey. serhatyanik@hotmail.com

${ }^{2}$ Okan University, Institute of Social Sciences, Isntabul, Turkey. ece.bs@hotmail.com

To cite this document

Yanik, S., Bas, E., (2017). Evaluation of IFRS17 insurance contracts standards for insurance companies. PressAcademia Procedia (PAP), V.6., p. 48-50.

Permanant link to this document: $\mathrm{http}: / /$ doi.org/10.17261/Pressacademia.2017.745

Copyright: Published by PressAcademia and limited licenced re-use rights only.

\begin{abstract}
Objective- The new IFRS 17 "Insurance Contracts" Standard, which could change the accounting of all enterprises drawing up insurance contracts and the investment contracts with discretionary participation feature radically, will be applied in the annual reporting periods starting on January 1, 2021 or after that date, and replace TFRS 4 "Insurance Contracts" standard that is currently in force. This study examines the IFRS 17 standard from the viewpoint of the insurance companies, and also discusses the revisions made within the scope of TFRS 4 that is in force until the start of the application of the IFRS 17 standard, and the accompanying right of exemption in application of the TFRS 9 "Financial Instruments" standard. Since there is no sufficient study on this subject in our country, it is targeted to contribute to understanding of the subject by including application examples in this study.

Methodology- This study uses case method, qualitative interview (in-depth interview), and review method as the research method. The basic reason for selecting this method is that the method is appropriate for the aim of the study, and an effective method investigating a special situation based on insurance companies systematically in the studies on the "Insurance Contracts" standard.

Findings- IFRS 17 will be beneficial for both investors and the insurance companies by requiring recognition of all insurance contracts consistently, and by solving the comparison problems created by the TFRS 4 . IFRS 17 requires an up-to-date measurement model in which the estimations are measured again in each reporting period. The measurement is based on the building blocks of the discounted, probability-weighted cash flows, a risk correction, and a contractual service margin representing the unearned profit of the contract. Within the scope of IFRS 17, the enterprises have an accounting policy option to recognize the changes in the discount rate or the other assumptions related to the financial risks in the profit or loss, or in the other comprehensive income. Within the scope of TFRS 4 , on the other hand, it will provide all companies drawing up insurance contracts with an option to recognize the fluctuation possible to occur when TFRS 9 is applied before implementation of the new insurance contracts standard in the other comprehensive income statement instead of profit or loss.

Conclusion- The IFRS 17 insurance contracts standard will replace TFRS 4, and ensure the creation of the single and consistent measurement model that meets the supplementary disclosure requirements intended for increasing the transparency for all insurance contracts prepared by the companies issuing reports in accordance with the International Financial Reporting Standards. Within this scope, the Insurance liabilities will be recognized by using updated values instead of historical cost, and the readers of financial statements will have been provided with more effective and accurate information.
\end{abstract}

Keywords: Turkish Accounting Standard (TAS), International Financial Reporting Standards, insurance companies, insurance contracts, financial instruments

JEL Codes: M41, M42

YENI UYGULANACAK OLAN UFRS 17 SIGORTA SÖZLEŞMELERI STANDARDININ SIGORTA ŞIRKETLERi AÇISINDAN DEĞERLENDIRILMESi

\section{ÖZET}

Amaç- Sigorta sözleşmeleri ile isteğe bağlı katılım özelliğine sahip yatırım sözleşmeleri düzenleyen tüm işletmelerin muhasebesini temelden değiştirebilecek olan yeni UFRS 17 "Sigorta Sözleşmeleri" standardı, 1 Ocak 2021 tarihinde veya bu tarihten sonra başlayan yıllık 
raporlama dönemlerinde uygulanacak olup yürürlükte olan TFRS 4 " Sigorta Sözleşmeleri "standardının yerini alacaktır. Bu çalışmada UFRS 17 standardı Sigorta işletmeleri açısından incelenmiş olunup, UFRS 17 standardı uygulanmaya başlayana dek mevcut durumda yürürlükte olan TFRS 4 kapsamında yapılan değişiklikler ve beraberinde getirdiği TFRS 9 “ Finansal Araçlar" standardının uygulanmasındaki muafiyet hakkı da ele alınmıştır. Ülkemizde bu konu ile ilgili yeterli sayıda çalışma yapılmamış olması nedeniyle uygulamaya dönük örneklere yer verilerek konunun anlaşılmasına katkı sağlanması hedeflenmiştir.

Yöntem- Söz konusu çalışmada araştırma yöntemi olarak örnek olay yöntemi, nitel görüşme (derinlemesine görüşme) ve inceleme metodu kullanılmıştır. Bu yöntemin seçilmesinin en temel nedeni, yöntemin çalışmanın amacıyla uygun olması, "Sigorta Sözleşmeleri" standardı çalışmalarında sigorta işletmeleri alanına dayalı özel bir durumun veya sistematik bir araştırmasını yapan etkili bir yöntem olmasıdır.

Bulgular- UFRS 17, tüm sigorta sözleşmelerinin tutarlı bir şekilde muhasebeleştirilmesini gerekli kılarak, UFRS 4'ün yarattığı karşılaştırma sorunlarını çözerek, hem yatırımcıların hem de sigorta şirketlerinin bu durumdan faydalanmasını sağlayacaktır. UFRS 17, her raporlama döneminde tahminlerin yeniden ölçüldüğü bir güncel ölçüm modeli gerektirir. Ölçüm, iskonto edilmiş, olasılık ağırlıklı nakit akışlarının yapı taşlarına, bir risk düzeltmesine ve sözleşmenin kazanılmamış karını temsil eden sözleşme uyarınca bir hizmet marjına dayanır.UFRS 17 kapsamında işletmeler, iskonto oranındaki ve finansal risklere ilişkin diğer varsayımlardaki değişikliklerin kar veya zararda veya diğer kapsamlı gelirde muhasebeleştirilmesi için bir muhasebe politikası seçeneğine sahiptir. TFRS 4 kapsamında ise Sigorta sözleşmeleri tanzim eden tüm şirketlere yeni sigorta sözleşmeleri standardı uygulamaya geçmeden önce TFRS 9 uygulandığında ortaya çıkabilecek olan dalgalanmayı kar veya zararda muhasebeleştirmek yerine diğer kapsamlı gelir tablosunda muhasebeleştirme opsiyonu sağlayacaktır.

Sonuç- UFRS 17 sigorta sözleşmeleri standardı, UFRS 4'ün yerini alacak ve Uluslararası Finansal Raporlama Standartları uyarınca raporlayan şirketler tarafından çıkarılan tüm sigorta sözleşmeleri için şeffaflı̆̆ın artırılmasına yönelik tamamlayıcı açıklama gerekliliklerine sahip tek ve tutarlı ölçüm modelinin oluşturulmasını sağlayacaktır. Bu kapsamda Sigorta yükümlülükleri, tarihi maliyet yerine güncel değerler kullanılarak muhasebeleştirilecek ve finansal tablo okuyucularına daha etkin ve doğru bir bilgi sağlanmış olunacaktır.

Anahtar Kelimeler: TMS, UFRS, sigorta şirketleri, sigorta sözleşmeleri, finansal araçlar

JEL Kodları: M41, M42

\section{GiRiş}

Sigorta İşletmeleri muhasebe uygulamaları açısından diğer sektörlere göre çok farklı bir muhasebe organizasyonuna sahiptir. Bir üretim işletmesinde mamulün maliyetine yüklenen tutarları üretilen mamul adedine bölerek birim üretim maliyetini bulabilirken, Ticaret işletmesi satacağı malın maliyetini alış anında tespit edebiliyorken Sigorta sektöründe gerçekleşmiş bir maliyet bulunmamaktadır. Çünkü üretim işletmesi satacağı mamulü önce üretir ardından mamulün üretim maliyeti üzerine diğer giderlerini ve kar payını da ekleyerek satış fiyatını ortaya çıkartırken Sigorta işletmelerinde satış önceden yapılmakta, giderler ise ileride beklenen riskin ortaya çıkması durumunda belli olmaktadır. Satılan police için hasar ödenmesi durumu sözleşme süresince belirsiz kalmaktadır. Bu sebeple, Sigorta işletmelerinde maliyet hesapları ve kayıt sistemleri diğer sektörlere göre farklılık göstermektedir. Yapılan izahatlar ışığında, üretim ve ticaret işletmelerinin hazırladığı finansal tablolar Sigorta sektörünün ihtiyacını karşılamamaktadır.

Sigorta şirketlerinde kar/zararın doğru gösterilmesinin imkanı yoktur. Çünkü şirketlerin ayırmış oldukları karşılık tutarları geçmiş yıl istatistiklerinden hareketle hazırlanmıştır ve bu karşılıklarda sapma olması doğal karşılanmaktadır. İstatistiksel hesaplarla ayrılan karşılığın şirketin gelirinden gider olarak düşülmesi de şirketin karlılı̆ının değişmesine neden olmaktadır (Kırlıoğlu vd.,2016).

Sigorta sözleşmeleri için özel olarak hazırlanan "UFRS 4 Sigorta Sözleşmeleri” standardı iki kısımdan oluşmaktadır. Standardın birinci kısmı Mart 2004'te hazırlanış olup bu stadartla Sigorta şirketlerinin Sigorta sözleşmelerinde ortaya çıkan gelecekteki belirsiz nakit akışları, zamanlama ve miktarlarında iyileştirme yapılması hedeflenmektedir. Ülkemizde TFRS 4 ile mevcut Sigorta muhasebe sisteminin zayıflıklarının ve tutarsızlıklarının ortadan kaldıııması hedeflenmektedir. Ancak Türkiye'de Sigorta sektöründe henüz TFRS 4 uygulanmamaktadır. Zira Sigorta sektörüne ilişkin muhasebe uygulamaları Hazine Müşteşarlığının çıkarmış olduğu Yönetmelikler kapsamında gerçekleştirilmektedir. Bu yönetmeliklerden bir tanesi TMS 1: Finansal Tabloların Sunuluşu ve TFRS 4: Sigorta Sözleşmeleri Standartlarını kapsam dışında bırakmaktadır (Kırlıoğlu vd.,2016).

Sigorta sözleşmeleri ile isteğe bağlı katılım özelliğine sahip yatırım sözleşmeleri düzenleyen tüm işletmelerin muhasebesini temelden değiştirebilecek olan yeni UFRS 17 "Sigorta Sözleşmeleri" standardı, 1 Ocak 2021 tarihinde veya bu tarihten sonra başlayan yıllık raporlama dönemlerinde uygulanacak olup yürürlükte olan TFRS 4 " Sigorta Sözleşmeleri "standardının yerini alacaktır.

\section{VERI, YÖNTEM, BULGULAR, ANALIZ}

Yeni uygulanacak olan UFRS 17 Sigorta Sözleşmeleri Standart, 2004 yılında ara dönem standardı olarak getirilmiş olan UFRS 4'ün yerini alacak olup erken uygulama seçeneği ile birlikte 1 Ocak 2021'den itibaren geçerli olacaktır. Sigorta yükümlülükleri, tarihi maliyet yerine güncel değerler kullanılarak muhasebeleştirilecek ve Finansal tablo okuyucularına daha yararlı olan bu bilgiler, düzenli olarak güncellenecektir (PwC, 2017).

UFRS 17, tüm sigorta sözleşmelerinin tutarlı bir şekilde muhasebeleştirilmesini gerekli kılarak, UFRS 4'ün yarattığı karşılaştırma sorunlarını çözerek, hem yatırımcıların hem de sigorta şirketlerinin bu durumdan faydalanmasını sağlayacaktır. UFRS 17, her raporlama döneminde tahminlerin yeniden ölçüldüğü bir güncel ölçüm modeli gerektirir. Ölçüm, iskonto edilmiş, olasılık ağırlıklı nakit akışlarının yapı taşlarına, bir risk düzeltmesine ve sözleşmenin kazanılmamış karını temsil eden sözleşme uyarınca bir hizmet marjına dayanır. UFRS 17 kapsamında işletmeler, iskonto oranındaki ve finansal risklere ilişkin diğer varsayımlardaki değişikliklerin kar veya zararda veya diğer kapsamlı gelirde muhasebeleştirilmesi için bir muhasebe politikası seçeneğine sahiptir. UFRS 4 bugüne kadar sigorta şirketlerinin kendi ulusal muhasebe standartlarını kullanarak sigorta sözleşmelerinin muhasebeleştirilmesini sağlarken, çok sayıda farklı yaklaşımla sonuçlandı. Bu durumda yatırımcıların benzer şirketlerin mali performansını karşılaştırması zorlaştı. 
TFRS 4 kapsamında ise Sigorta sözleşmeleri tanzim eden tüm şirketlere yeni sigorta sözleşmeleri standardı uygulamaya geçmeden önce TFRS 9 uygulandığında ortaya çıkabilecek olan dalgalanmayı kar veya zararda muhasebeleştirmek yerine diğer kapsamlı gelir tablosunda muhasebeleştirme opsiyonu sağlayacaktır. Bir başka deyişle, UFRS 17, bir işletme tarafından tanzim edilen sigorta sözleşmeleri, tüm reasürans sözleşmeleri ve işletmenin ayrıca sigorta sözleşmeleri tanzim ettiği durumda isteğe bağlı katılım özelliklerine sahip yatırım sözleşmelerine uygulanır. Birincil amacı hizmet sunumu olan sabit ücretli hizmet sözleşmeleri için, işletmelerin UFRS 17 veya UFRS 15 uyarınca muhasebeleştirecekleri bir muhasebe politikası seçeneği vardır. Saklı türevler ve farklı yatırım ve hizmet unsurları, ilgili IFRS'lere göre ayrıştırılmalı ve ayrı ayrı muhasebeleştirilmelidir. İhtiyari olarak diğer unsurların ayrıştırılması yasaktır.

Sunum ve ölçüm için, ilk muhasebeleştirmede, işletmelerin bir portföyü (yani benzer risklere tabi olan ve tek bir havuz olarak yönetilen sözleşmeler) üç grup sözleşmeye ayırması gereklidir; ivazlı, ivazlı olma riski bulunmayan, ve bakiye sözleşmeler. Bir yıldan daha fazla süre ayrı olarak ihraç edilen sözleşmeler aynı grupta olmamalıdır.

Gelecekteki hizmetlerle ilgili nakit akışlarındaki değişim, sözleşme uyarınca hizmet marjı karşılığında muhasebeleştirilmelidir. Sözleşme uyarınca hizmet marjı negatif olamaz, bu nedenle kalan sözleşme uyarınca hizmet marjından daha büyük olan gelecekteki nakit akışlarındaki değişiklikler kar veya zararda muhasebeleştirilir. Faiz, sözleşme uyarınca hizmet marjı üzerine, bir sözleşmenin ilk muhasebeleştirilmesinde kitlenen oranlardan eklenmektedir. Sunulan hizmeti yansıtmak için, her dönem sözleşme uyarınca hizmet marjı zamanın geçmesine bağlı olarak kar veya zararda muhasebeleştirilir. (PwC,2017).

UFRS 17 kapsamında işletmelerin uygulayabileceği bir diğer muhasebe politikası ise iskonto oranındaki ve finansal risklere ilişkin diğer varsayımlardaki değişikliklerin kar veya zararda veya diğer kapsamlı gelirde muhasebeleştirilmesidir.

\section{SONUÇ}

UFRS 17 sigorta sözleşmeleri standardı, UFRS 4'ün yerini alacak ve Uluslararası Finansal Raporlama Standartları uyarınca raporlayan şirketler tarafından çıkarılan tüm sigorta sözleşmeleri için şeffaflığın artırılmasına yönelik tamamlayıcı açıklama gerekliliklerine sahip tek ve tutarlı ölçüm modelinin oluşturulmasını sağlayacaktır. Bu kapsamda Sigorta yükümlülükleri, tarihi maliyet yerine güncel değerler kullanılarak muhasebeleştirilecek ve finansal tablo okuyucularına daha etkin ve doğru bir bilgi sağlanmış olunacaktır.

UFRS 17, işletmeleri finans, aktüeryal, sistem geliştirme alanlarının (örneğin, ürün tasarımı ve dağıtımı, gözden geçirilmiş teşvik ve daha geniş ücret politikalarının geliştirilmesi ve iş planlamasına giren yeniden yapılandırılmış bütçeleme ve tahmin metodolojileri) ötesinde etkileyecektir. Nakit vergi pozisyonu ve temettüler üzerinde hem geçmiş hem de ilerleyen dönemlerde etkisi olabilir. UFRS 17'nin uygulanması üç yıldan fazla sürebileceği göz önünde bulundurulmalıdır Bir uygulama yol haritası oluşturmak için fark analizi ve etki değerlendirmeleri, işletmelerin ayrıntılı uygulama projelerine başlamasını sağlayabileceği hususu dikkate alınmalıdır.

\section{KAYNAKLAR}

Akbulut, A. (2015) , Karşılaştırılmalı TMS/TFRS-Vergi Uygulamaları ve Sonuçları, İstanbul: Maliye Hesap Uzmanları Derneği: $1213-1219$

Ciesielski, J. T., \& Weirich, T. R. (2015) Revenue Recognition: How It Will Impact Three Key Sectors, Journal of Corporate Accounting \& Finance, 26(3), pp. 31-39.

Çaldağ, Y. (1976), Sigorta İşletmeleri ve Muhasebenin İncelenmesi, Ankara: Ankara İktisadi ve Ticari İlimler Akademisi Yayınları, Ss. 77

Epstein, B. ve Jermakowicz E. (2008), IFRS Policies and Procedures, USA: John Wiley \& Sons Inc, ss. 86-8

7IAS 17 (2017), https://www.iasplus.com/en/standards/ifrs/ifrs-17 (Erişim Tarihi 30.09.2017)

IAS 17 Review (2017), http://ec.europa.eu/internal_market/accounting/docs/consolidated/ias17_en.pdf, (Erişim Tarihi 30.09.2017)

Insurance Contracts (2017), http://www.ifrs.org/projects/2017/insurance-contracts/,(Erişim Tarihi 30.09.2017)

Karacan, S., (2013), Sigorta İşletmeleri ve Muhasebe Sistemi, S.Aslanoğlu (Ed.) Banka ve Sigorta Muhasebesi, Eskişehir: Anadolu Üniversitesi, SS. 170-196.

Kırlığlu, H. ve Demirci, Ş. (2016), TMS ve TFRS'ler ile Tam Uyumlu Sigorta Şirketlerinde Muhasebe Uygulamaları, Nobel Yayınları,Ankara, Ss.2-140.

Özkan, T. (2007), TDHP Sisteminde Sigorta Muhasebesi, S. Oksay (Ed)., Sigorta Araştırma ve İnceleme Yayınları 10, İstanbul, TSEV, SS.48.Pekiner,

PwC, Sigorta Sözleşmeleri Standardı (2017), https://www.pwc.com.tr/tr/hizmetlerimiz/denetim/ufrs-raporlamasi/bultenler/ufrs-17-sigortasozlesmeleri-standardi.html, (Erişim Tarihi 30.09.2017)

Yanık, S. (2016), Sigorta Acentelerinde Yönetim ve Muhasebe Uygulamaları, Seçkin Yayınları, İstanbul, Ss.30-120.

Yanık, S. ve Özerhan, Y. (2015), TMS TFRS Açıklamalı ve Örnek Uygulamalı Türkiye Muhasebe Standartları Türkiye Finansal Raporlama Stand., TURMOB Yayınları, Ankara, ss. 30

Türkiye Sigorta Birliği (TSB), https://www.tsb.org.tr/sigortacilik-hesap-plani.aspx?pagelD=826, (Erişim Tarihi 01.11.2017) 